\title{
Deadly combination of E-cigarettes has become a popular-Induced lung injury and Influenza: case report
}

Bindu H. Akkanti ${ }^{1}$, Rahat Hussain ${ }^{1}$, Manish K. Patel ${ }^{2}$, Jayeshkumar A. Patel ${ }^{2}$, Kha Dinh ${ }^{1}$, Bihong Zhao ${ }^{3}$, Shaimaa Elzamly ${ }^{3}$, Kevin Pelicon², Klemen Petek², Ismael A. Salas de Armas², Mehmet Akay², Biswajit Kar², Igor D. Gregoric ${ }^{2}$ and L. Maximilian Buja ${ }^{3^{*}}$ (1)

\begin{abstract}
Background: E-cigarette and vaping use-associated acute lung injury (EVALI) has been recently recognized as a complication in individuals who use vaping devices. Another consideration is that EVALI may have an adverse influence on the outcome of intercurrent respiratory infections. We document this deadly combination in the case of a young man who had EVALI and simultaneous Influenza-A infection leading to severe Acute Respiratory Distress Syndrome (ARDS).

Case presentation: A 27-year-old male with a history of tobacco and vaping use was admitted to hospital after two weeks of flu-like symptoms, diarrhea and vomiting. A chest x-ray was consistent with multifocal pneumonia, and microbiological tests were positive for Influenza-A and methicillin-sensitive Staphalacoccus aureus (MSSA). Bronchoscopy provided evidence of acute inhalational injury. After admission, he acutely decompensated with severe hypoxia and hypotension; he required intubation, sedation and vasopressors. He developed sepsis with acute kidney failure, liver failure, biventricular systolic dysfunction and severe rhabdomyolysis. He was placed on veno-venous (W) extracorporeal membrane oxygenation (ECMO) initially and later changed to Veno-Arterial (VA) ECMO. Nevertheless, the patient continued to deteriorate, and he expired two weeks after admission.
\end{abstract}

Conclusion: This case documents that EVALI can act as a major factor leading a respiratory infection to progress into severe ARDS with a fatal outcome.

Keywords: Vaping, Influenza, Acute respiratory distress syndrome (ARDS), Diffuse alveolar damage (DAD), Case report

\section{Introduction}

Electronic cigarettes, or vaping devices, have become increasingly popular in recent years. The short- and longterm health effects of e-cigarette use are still poorly understood but hundreds of cases of e-cigarette or vaping product use-associated lung injury (EVALI) have

\footnotetext{
*Correspondence: I.maximilian.buja@uth.tmc.edu

${ }^{3}$ Department of Pathology and Laboratory Medicine, McGovern Medical School, The University of Texas Health Science Center at Houston (UTHealth), 6431 Fannin St. MSB 2.276, Houston, TX 77030, USA

Full list of author information is available at the end of the article
}

been reported [1]. In the USA, the number of e-cigarette related emergency department visits has been slowly increasing since 2017 [2]. The use of vaping devices is especially prevalent in the age group of 11 to 34 -year-olds [1]. While the mechanism of lung injury in patients who vape is under investigation at the state and federal levels, vitamin $\mathrm{E}$ acetate, a chemical used to dilute tetrahydrocannabinol (THC) oil in vape cartridges, has emerged as one of the likely causes of EVALI [3-7]. In January 2020, the FDA finalized a policy that will prioritize

(c) The Author(s). 2020 Open Access This article is licensed under a Creative Commons Attribution 4.0 International License, which permits use, sharing, adaptation, distribution and reproduction in any medium or format, as long as you give appropriate credit to the original author(s) and the source, provide a link to the Creative Commons licence, and indicate if changes were made. The images or other third party material in this article are included in the article's Creative Commons licence, unless indicated otherwise in a credit line to the material. If material is not included in the article's Creative Commons licence and your intended use is not permitted by statutory regulation or exceeds the permitted use, you will need to obtain permission directly from the copyright holder. To view a copy of this licence, visit http://creativecommons.org/licenses/by/4.0/ The Creative Commons Public Domain Dedication waiver (http://creativecommons.org/publicdomain/zero/1.0/) applies to the data made available in this article, unless otherwise stated in a credit line to the data. 
enforcement against certain e-cigarette flavors and manufacturers of products that are targeted to minors or have failed to take adequate measures to prevent minors' access [8]. The aim is to significantly reduce the prevalence of vaping among children while still providing a viable alternative for current combustible tobacco smokers, seeking to cut back [4]. We present a fatal case of EVALI complicated by Influenza-related Acute Respiratory Distress Syndrome (ARDS) (Table 1). This case documents that EVALI can be a major predisposing and contributing factor causing a respiratory infection to progress into severe ARDS with a fatal outcome.

\section{Case presentation}

\section{History}

A 27-year-old African American male with a history of cigarette tobacco use (2 years) and vaping of tetrahydrocannabinol (THC) presented with two weeks of nonproductive cough, subjective fever, rhinorrhea, chills, myalgia, diarrhea, and vomiting. He had reported to an outside emergency room 2 days prior and was diagnosed with a viral upper respiratory tract infection and discharged. Despite over-the-counter medication and fluids, he experienced no improvement of his symptoms. However, he continued to have fever, chills, myalgia, rhinorrhea, and dry cough, and so he returned to an outside hospital in mid-December, 2019.

\section{Table 1 Timeline}

Patient is a 27-year-old African American male.

Patient has a 2-year history of cigarette tobacco use and vaping of tetrahydrocannabinol $(\mathrm{THC})$

Patient presents to an emergency room with a 2-week history of nonproductive cough, subjective fever, rhinorrhea, chills, myalgia, diarrhea, and vomiting. He is diagnosed with a viral upper respiratory tract infection and is discharged.

Two days later, in mid-December 2019, because of worsening symptoms, patient is admitted to an outside hospital.

Infection work up is positive for Influenza-A by nasal swab, and sputum grows methicillin-sensitive Staphylococcus aureus (MSSA) a few days later.

Initial chest $\mathrm{x}$-ray reveals patchy infiltrates of the right upper and bilateral lower lobes that are consistent with multifocal pneumonia (Fig. 1). Patient's respiratory status declines rapidly, and he is transferred to the intensive care unit (ICU) and intubated for respiratory failure.

Bronchoscopy shows evidence of damage to the trachea and upper bronchi, likely due to vaping.

Treatment is started with vitamin C, thiamine, hydrocortisone and multiple antibiotics (vancomycin, cefepime, azithromycin and doxycycline) for concern of sepsis as well as oseltamivir for Influenza A. Patient's clinical condition continues to deteriorate, and he is transferred for a higher level of care.

Patient is treated with V-V ECMO, VA-ECMO and IABP.

Patient develops acute renal failure, liver failure, biventricular systolic dysfunction and rhabdomyolysis.

Patient expires after a total hospital course of 2 weeks.

Autopsy is performed and reveals severe DAD and lipid-laden macrophages consistent with lipoid pneumonia.

Abbreviations: ECMO extracorporeal membrane oxygenator, DAD diffuse alveolar damage, IABP intra-aortic balloon pump, $V$-A veno-arterial, $V$ - $V$ veno-venous
On admission, he was tachypneic and tachycardic with leukocytosis and lymphopenia. An initial chest x-ray revealed patchy infiltrates of the right upper and bilateral lower lobes that were consistent with multifocal pneumonia (Fig. 1). A respiratory pathogen panel was positive for Influenza A (real time polymerase chain reaction test on nasal swab), and, in a few days later, his sputum grew methicillin-sensitive Staphylococcus aureus (MSSA). Tests for other pathogens were negative. Upon admission to the intensive care unit (ICU), his initial complete blood count $(\mathrm{CBC})$ was remarkable for white blood cell count (WBC) of $9.8 \mathrm{k} / \mathrm{gL}$ with $92.4 \%$ neutrophils and $3.8 \%$ lymphocytes and a platelet count of $97 \mathrm{k} / \mathrm{gL}$. His basic metabolic panel (BMP) was remarkable for creatinine of $2.34 \mathrm{mg} / \mathrm{dL}$, AST of $343 \mathrm{u} / \mathrm{L}$, ALT of $144 \mathrm{u} / \mathrm{L}$, lactic acid of $9.8 \mathrm{mMol} / \mathrm{L}$, and procalcitonin of $26.86 \mathrm{ng} / \mathrm{mL}$. Ferritin was elevated at $5181 \mathrm{ng} / \mathrm{mL}$ during the hospitalization.

\section{Differential diagnosis}

The patient's clinical presentation, imaging and laboratory results were consistent with acute pneumonia. The microbiological workup confirmed Influenza $\mathrm{A}$ and MSSA. The patient's frequent use of e-cigarettes was a possible predisposing factor for EVALI and vapingrelated lipoid pneumonia. Additionally, given significant elevation in ferritin with subsequent severe leukopenia, lymphopenia and thrombocytopenia, acquired hemophagocytic lymphohistiocytosis (HLH) was considered in the differential diagnosis.

\section{Treatment}

His respiratory status declined rapidly, and he was transferred to the intensive care unit (ICU) and intubated for respiratory failure. The patient underwent a bronchoscopy which revealed copious airway secretions and a thick, sloughing, erythematous mucosa. Bronchoalveolar lavage (BAL) yielded degenerated material with benign pulmonary elements and acute inflammation, but no signs of malignancy. The bronchoscopy revealed severely denuded airways throughout the lungs consistent with an inhalational injury likely due to vaping (see bronchoscopic images, Fig. 2).

He had no clinical history of inhalational injury other than the vaping exposure. He had severe progressive refractory respiratory failure despite maximal ventilatory strategies with a progressive increase in airway pressure and dropping Pa02/Fi02 ratio. At this time, he became hypotensive and was vasopressor dependent. Treatment was started with vitamin $\mathrm{C}$, thiamine, hydrocortisone and multiple antibiotics (vancomycin, cefepime, azithromycin and doxycycline) for concern of sepsis as well as oseltamivir for Influenza A. Despite antibiotic treatment, his hypoxic respiratory failure further progressed and he 

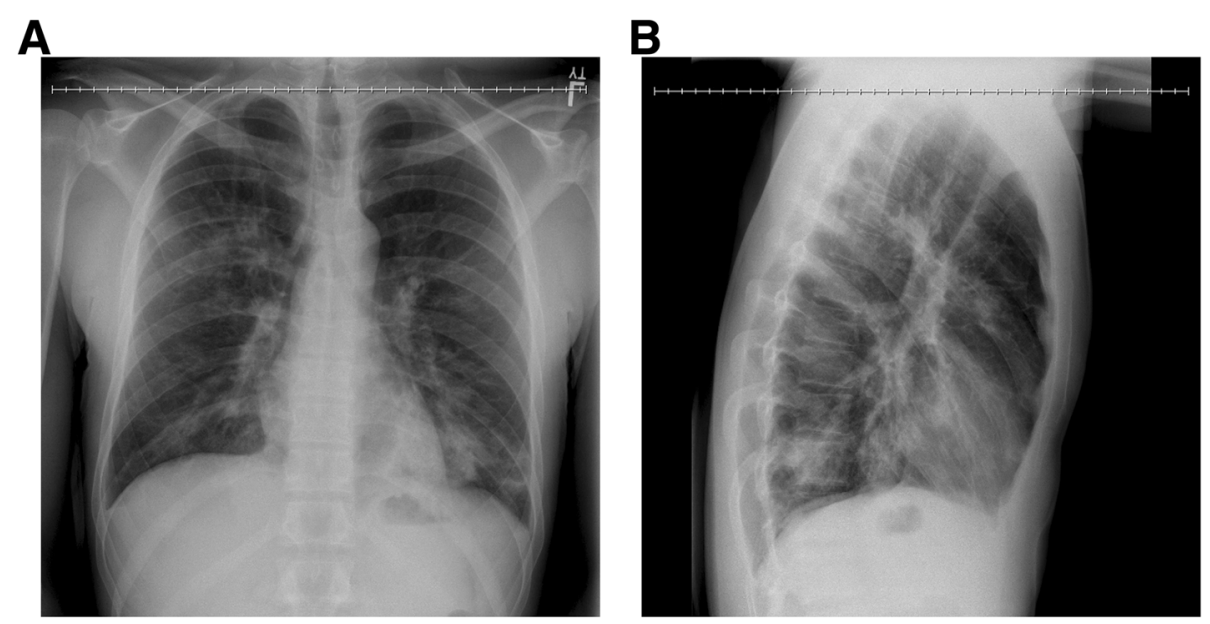

Fig. 1 Chest x-ray on admission; PA and lateral view. Patchy infiltrates can be seen in both lower lobes and the right upper lobe

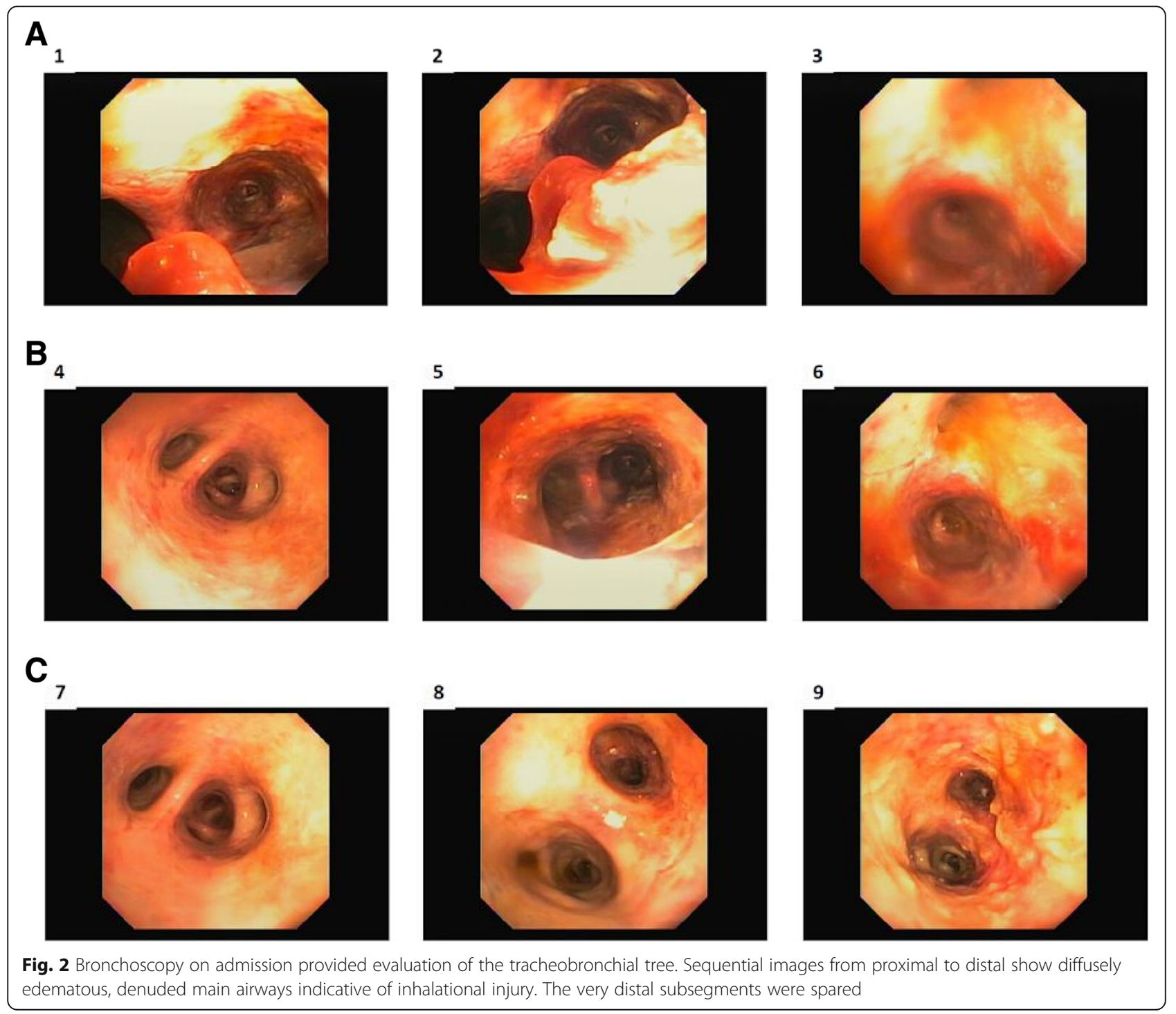


required aggressive ventilatory support with a positive end-expiratory pressure (PEEP) of up to 30. The patient's $\mathrm{Pa} 02 / \mathrm{Fi} 02$ ratio was only 37 when the extracorporeal membrane oxygenation (ECMO) team was contacted and a bilateral femoral veno-venous (V-V) ECMO was placed at the spoke institution as part of our mobile ECMO program and patient was brought to our hub institution. After the procedure he was stable enough to be transferred to our facility. Despite the $\mathrm{V}-\mathrm{V}$ ECMO, the patient required multiple vasopressors and although his lactic acid decreased initially, there was a progressive need for escalatory support and patient was converted patient from V-V ECMO to veno-arterial (VA) ECMO. Given severe sepsis with shock, the peripheral V-A ECMO was deemed to be insufficient to provide hemodynamic support, and he was subsequently placed on central V-A ECMO to improve end-organ function. The patient's clinical course was complicated by acute kidney failure for which he required dialysis, liver failure and encephalopathy which was likely secondary to his metabolic derailment and sepsis. He also experienced multiple episodes of atrial fibrillation with rapid ventricular response for which he was successfully cardioverted three times. A transthoracic echocardiogram showed a severely dilated right ventricle as well as biventricular systolic dysfunction. Due to a worsening pulmonary edema, he was emergently placed on an intra-aortic balloon pump (IABP). Although the CXR showed subsequent improvement in aeration with improvement in minute ventilation on the ventilator (Fig. 3), the patient also developed severe limb ischemia with skin mottling and ecchymoses on his extremities, trunk, nose and ears. Sepsis and cytokine storm with severe vasoplegia requiring vasopressors were determined to the ongoing issue. Severely diminished tibial flow and thrombi in the bilateral posterior tibial arteries was seen on vascular ultrasound and out of concern for compartment syndrome the patient underwent a fasciotomy. During this time, patient was awake, alert and communicative with the family at the bedside. Despite our best efforts, non-viable muscle was seen in all four compartments bilaterally and a bilateral through-knee amputation was performed. Confronted with the patient's poor prognosis, the family decided to suspend life-supporting measures in favor of transition to comfort care. The patient expired shortly after the IABP and ECMO were turned off. In total, the patient spent two weeks in the hospital. The family consented to an autopsy.

\section{Autopsy}

The most important findings in his autopsy are in the lungs, which were grossly solid and extremely heavy (Fig. 4a). No thromboemboli or masses were found in the lungs. The pleural surfaces were dusky and uneven with anthracotic pigment deposition. The pulmonary parenchyma was congested with a mottled appearance due to areas of consolidation, hemorrhage, and necrosis. Histologically, features of diffuse alveolar damage (DAD) were seen (Fig. 4b) with numerous hyaline membranes and alveolar fibrin deposits, together with exuberant necrotizing lobar pneumonia (Fig. 4c). In the nonnecrotic lung parenchyma, many foamy histiocytes are present in the alveolar spaces and lipid-containing cells are seen in the alveolar walls, highlighted by special stain Oil-Red O (Fig. 4d). Multifocal, extensive lymphoplasmacytic pericarditis was present, but there was no evidence of myocarditis. Patchy lymphoplasmacytic interstitial infiltrates were found in both kidneys. DAD was considered to be the immediate cause of death of the patient. A lung specimen was sent to the Infectious Disease Laboratory of the Center for Disease Control. The specimen tested positive for influenza virus and negative for SARS-CoV-2 virus.

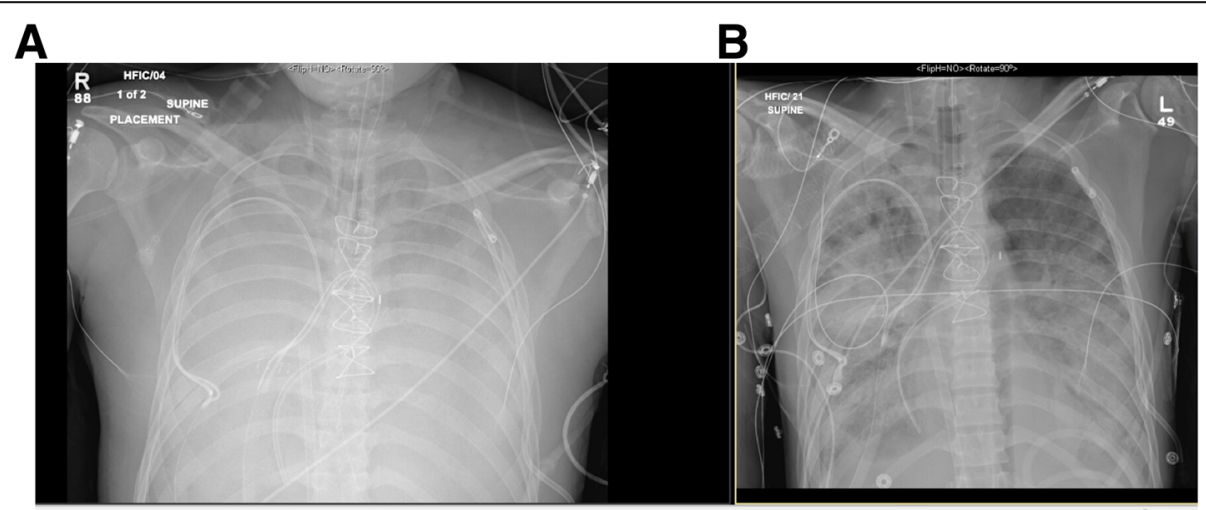

Fig. 3 a Chest x-ray on admission to ICU one day after initial CXR at admission showing diffuse infiltrates with loss of lung volumes. b Improvement in aeration noted in four days after cannulation with ECMO 

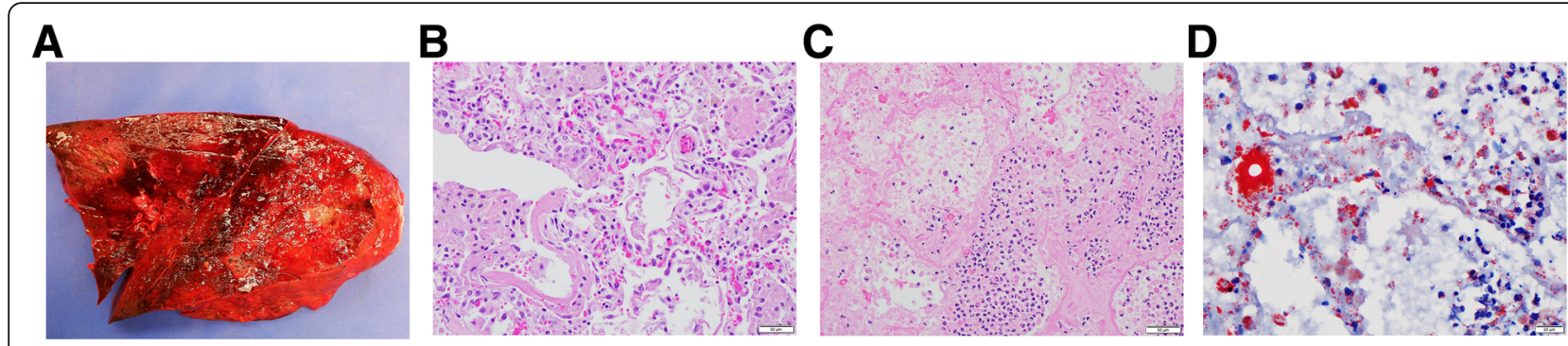

Fig. 4 a Gross photo of a cut surface of lung, which shows solid, hemorrhagic areas with necrosis. b Microscopic photo of diffuse alveolar damage (DAD) in the exudative phase, with hyaline membrane formation, fibrinous and cellular exudate in alveolar spaces. $\mathbf{c}$ Large area of necrotizing bacterial pneumonia. d Special stain Oil Red O, demonstrating lipid containing macrophages in alveolar spaces and alveolar wall

\section{Discussion}

The critical questions in this case are how and why a young man would die after such a short clinical course which began as an upper respiratory infection. The patient had lymphopenia suggesting he was immunocompromised. Why? By reviewing the patient's history, we propose that the patient's vaping with inhalation of a Vitamin $\mathrm{E}$ acetate and tetrahydrocannabinol mixture had a major role. In our case, the Oil Red O stain, which stains the lipid droplets in macrophages/ histiocytes, was strongly positive in the sections from the patient's lungs. This is supporting evidence of vaping, but it is not specific [9-11]. However, acute inhalational injury was documented by video bronchoscopy, and this provided confirmatory evidence of the vaping-induced lung injury [3-7, 12, 13].

Influenza is one of the consistent causes of death attributed to viral pneumonias every year [14]. EVALI due to vaping has been recently recognized as a concern in young patients who use vaping 168 devices [1-8]. Our patient had a complex of influenza-related severe lung injury and rhabdomyolysis further complicated by vaping of a mixture of Vitamin-E and THC. In an experimental murine model, chronic exposure to vapor from electronic nicotine delivery systems (ENDS) or e-cigarettes, independent of nicotine, did not result in pulmonary inflammation or emphysema, but chronic exposure to the vapor did produce aberrant phospholipids in alveolar macrophages and increased surfactant-associated phospholipids in the airways [15]. ENDS vapor exposure downregulated innate immunity against viral pathogens in resident macrophages. Furthermore, ENDS vaporexposed mice infected with influenza demonstrated enhanced lung inflammation and tissue damage. Altered innate immunity also has been implicated in chronic vaping related tracheobronchial and pulmonary injury in patients [13].

Recent reports have revealed that constituents of Eliquids with Vitamin-E (alpha-tocopherol) acetate (VEA) is the likely culprit in worsening respiratory failure in these patients [16-18]. Vaping is the process of inhaling an aerosol that is created by heating a liquid or wax containing various substances, such as nicotine, cannabinoids causing acute lung injury that can be lethal. Although never officially approved by the FDA, over the past few years, vaping/E-cigarettes has become a popular trend and has been considered "safer" alternative to smoking cigarettes, especially among young adults. The use of Ecigarettes has rapidly increased, and according to the most recent report by CDC released at the end of December 2019, 2506 cases of lung disease and more than 54associated deaths due to EVALI were reported [19]. Initial data shows that most patients use E cigarettes containing tetrahydrocannabinol (THC); some use nicotine while others used a combination of both nicotine and THC. EVALI should be suspected in patients who have a history of vaping or other use of e-cigarette-related products and have a pneumonia-like syndrome, progressive dyspnea, and/or worsening hypoxemia, all of which were found in our patient $[20,21]$. The main differential diagnosis for EVALI is community acquired pneumonia (CAP) which can be treatable with antibiotics. The exact mechanism of the lung injury in vaping patients is not fully understood. However, vaping increases the susceptibility of the respiratory tract to both pathogenic and opportunistic infectious agents due to immune dysfunction. In one study, the inflammatory cytokines like Interleukin (IL)- 6 and IL-I were highly elevated in e-cigarette users when compared with non-users [21].

Bronchoscopy in our patient showed severely denuded airways as seen in inhalational injury-a finding that has not been previously reported with vaping-related illnesses. Additionally, vaping likely triggered the respiratory failure in this influenza patient-another new finding. Other striking findings under microscopic examination were the relatively diffuse epicardial lymphoplasmacytic infiltrate and patchy interstitial lymphoplasmacytic infiltrate in both kidneys, likely related to viral infection.

Although VV ECMO initially rescued the patient, influenza-related biventricular dysfunction and fatal rhabdomyolysis with CK elevation $>200,000$ contributed to the patient's decompensation. 
Influenza associated rhabdomyolysis has been previously reported in case reports in literature [22-31]. Recent review of literature in 2015 revealed twelve case reports with CK levels ranging from 1317 to 1,127,000 with mean value of 206, 908, with survival of $83 \%$ [18]. An additional six cases have been reported in the literature since then [25-31]. It is quite plausible that influenza related rhabdomyolysis is much more common and only the severely ill are being reported in the literature. Escalation of his cannulation to central cannulation gave him the best chance at perfusion possible; despite his completely intact neurologic status, efforts were unable to salvage the extremities. We would like to report that based on biomarker profile (lymphopenia, viral pneumonia, progressive ARDS, ferritin elevation), this is a inflammatory profile that is akin to poor survival reported in COVID-19, and this came true in Influenza as expected [32].

COVID-19 disease has many parallels to our patient, but this patient presented in mid-December 2019 well before the first case of COVID-19 in Texas. Analysis of a lung sample by the CDC confirmed the presence of influenza virus and absence of SARS-CoV-2 virus. Nevertheless, with the ongoing epidemic of COVID-19, whose viral infection leads to a similar devastating course as the one described here, physicians should be aware of, and diagnose, vaping-related lung injury when determining treatment and prognosis, and recognize that COVID-19 like illness with cytokine storm, lymphopenia, severe refractory ARDS, and biventricular dysfunction can occur as noted in the past with influenza.

\section{Conclusion}

In conclusion, our case demonstrates that young, previously healthy individuals who indulge in vaping from modified e-cigarettes and develop intercurrent respiratory infection are at risk of developing severe and potentially fatal ARDS with underlying DAD. This case documents that EVALI can act as a major factor leading a respiratory infection to progress into severe ARDS with a fatal outcome.

\section{Abbreviations}

ARDS: Acute respiratory distress syndrome; AV: Arterio-venous; COVID19: Coronavirus infectious disease 2019; DAD: Diffuse alveolar damage; ECMO: Extracorporeal membrane oxygenation; EVALI: E-cigarette and vaping use-associated acute lung injury; IABP: Intra-aortic balloon pump 229; THC: Tetrahydrocannabinol; W: Veno-venous

\section{Acknowledgements}

NA

\section{Authors' contributions}

All of the authors contributed to the clinical and/or pathology aspects of the case and reviewed the manuscript for publication. All authors gave consent to be included as co-authors. The author(s) read and approved the final manuscript.

\section{Funding}

The study is funded entirely from local sources.

\section{Availability of data and materials}

All materials described in the manuscript will be freely available to any scientist wishing to use them for non-commercial purposes, without breaching participant confidentiality.

\section{Ethics approval and consent to participate}

This work conforms to the human subjects research policies of the Committee for the Protection of Human Subjects of The University of Texas Health Science Center at Houston and is covered by an approved protocol, HSC-MS-17-0040. Since the subject of this case report is deceased,informed consent cannot be obtained.

\section{Consent for publication}

Since the subject of this case report is deceased, informed consent regarding use of radiographs and photographs of pathology material cannot be obtained.

\section{Competing interests}

None of the authors have related competing interests, either financial or non-financial.

\section{Author details}

'Divisions of Pulmonary, Critical Care and Sleep Medicine, McGovern Medical School, Houston, TX, USA. ${ }^{2}$ Advanced Cardio-Pulmonary Therapeutics and Transplantation, McGovern Medical School, Houston, TX, USA. ${ }^{3}$ Department of Pathology and Laboratory Medicine, McGovern Medical School, The University of Texas Health Science Center at Houston (UTHealth), 6431 Fannin St. MSB 2.276, Houston, TX 77030, USA.

Received: 14 May 2020 Accepted: 1 July 2020

Published online: 09 July 2020

\section{References}

1. King BA, Jones CM, Baldwin GT, Briss PA. The EVALI and youth Vaping epidemics -implications for public health. N Engl J Med. 2020;382(8):689-91. https://doi.org/10.1056/NEJMp1916171.

2. Crotty Alexander LE, Ware LB, Calfee CS, et al. NIH Workshop Report: Ecigarette or Vaping 256 Product Use Associated Lung Injury (EVALI): Developing a Research Agenda. Am J Respir Crit 257 Care Med. 2020. https://doi.org/10.1164/rccm.201912-2332WS.

3. Blagev DP, Harris D, Dunn AC, Guidry DW, Grissom CK, Lanspa MJ. Clinical presentation, treatment, and short-term outcomes of lung injury associated with e-cigarettes or vaping: a prospective observational cohort study. Lancet. 2019;394(10214):2073-83. https://doi.org/10.1016/S01406736(19)32679-0.

4. Qarajeh R, Kitchen J. THC Vaping-Induced acute respiratory distress syndrome. Am J Med. 2020;133(4):e147-8. https://doi.org/10.1016/j.amjmed. 2019.09.015

5. Christiani DC. Vaping-induced acute lung injury. N Engl J Med. 2020;382(10): 960-2. https://doi.org/10.1056/NEJMe1912032.

6. Kligerman S, Raptis C, Larsen B, et al. Radiologic, pathologic, clinical, and physiologic findings of electronic cigarette or vaping product useassociated lung injury (EVALI): evolving knowledge and remaining questions. Radiology. 2020;294(3):491-505. https://doi.org/10.1148/radiol. 2020192585.

7. Carroll BJ, Kim M, Hemyari A, et al. Impaired lung function following ecigarette or vaping product use associated lung injury in the first cohort of hospitalized adolescents. Pediatr Pulmonol. 2020;55(7):1712-8. https://doi. org/10.1002/ppul.24787.

8. FDA finalizes enforcement policy unauthorized flavored cartridge- based ecigarettes that 261 appeal to children including fruit and mint. https://www hhs.gov/about/news/2020/01/02/fda-finalzes-enforcement-policyunauthorized-flavored-cartrige-based-e.cigarettes.html.

9. Youmans AJ, Harwood J. Vaping induced lung injury death in the United States. Am J Forensic Med Pathol. 2020;41(1):1-4. https://doi.org/10.1097/ PAF.0000000000000533.

10. Gay B, Field Z, Patel S, et al. Vaping-Induced Lung Injury: A Case of Lipoid Pneumonia Associated with E-Cigarettes Containing Cannabis. Case Rep 
Pulmonol. 2020;2020:7151834. Published 2020 Apr 3. https://doi.org/10. 1155/2020/7151834.

11. Ocampo-Gonzalez FA, Park JW. Cytologic features of vaping-induced lung injury: A case report. Diagn Cytopathol. 2020;48(2):174-6. https://doi.org/10. 1002/dc.24343.

12. Mittal A, Baig A, Zulfikar R, Sharma S. Chronic Vaping Related Tracheomalacia (TM): A Case of Vaping Induced Altered Innate Immunity that Culminated in Severe TM. Cureus. 2020;12(4):e7571. Published 2020 Apr 7. https://doi.org/10.7759/cureus.7571.

13. Bai C, Huang $H$, Yao X, et al. Application of flexible bronchoscopy in inhalation lung injury. Diagn Pathol. 2013;8:174. Published 2013 Oct 21. https://doi.org/10.1186/1746-1596-8-174.

14. Chow EJ, Doyle JD, Uyeki TM. Influenza virus-related critical illness: prevention, diagnosis, 266 treatment. Crit Care. 2019;23(1):214. Published 2019 Jun 12. doi:https://doi.org/10.1186/s13054-019-2491-9.

15. Madison MC, Landers CT, Gu BH, et al. Electronic cigarettes disrupt lung lipid homeostasis and innate immunity independent of nicotine. J Clin Invest. 2019;129(10):4290-304. https://doi.org/10.1172/JCl128531.

16. Boudi FB, Patel S, Boudi A, Chan C. Vitamin E Acetate as a Plausible Cause of Acute Vaping285 related IIIness. Cureus. 2019;11(12):e6350. Published 2019 Dec 11. https://doi.org/10.7759/cureus.6350.

17. Wu D, O'Shea DF. Potential for release of pulmonary toxic ketene from vaping pyrolysis of 288 vitamin E acetate. Proc Natl Acad Sci U S A. 2020; 117(12):6349-55

18. Duffy B, Li L, Lu S, et al. Analysis of Cannabinoid-Containing Fluids in Illicit Vaping Cartridges Recovered from Pulmonary Injury Patients: Identification of Vitamin E Acetate as a Major Diluent. Toxics. 2020;8(1):8. Published 2020 Jan 24. https://doi.org/10.3390/toxics8010008.

19. Werner AK, Koumans EH, Chatham-Stephens K, et al. Hospitalizations and deaths associated with EVALI. N Engl J Med. 2020;382(17):1589-98. https:// doi.org/10.1056/NEJMoa1915314.

20. Blount BC, Karwowski MP, Shields PG, et al. Vitamin E Acetate in Bronchoalveolar-Lavage 295 Fluid Associated with EVALI. N Eng/ J Med. 2020;382(80):697-705. https://doi.org/10.1056/NEJMoa1916433.

21. ArRejaie AS, Al-Aali KA, Alrabiah M, et al. Proinflammatory cytokine levels and peri-implant parameters among cigarette smokers, individuals vaping electronic cigarettes, and non smokers. J Periodontol. 2019;90(4):367-74. https://doi.org/10.1002/JPER.18-0045a.99.

22. Ayala E, Kagawa FT, Wehner JH, Tam J, Upadhyay D. Rhabdomyolysis associated with 2009 influenza a (HINI). JAMA. 2009;302(17):1863-4. https:// doi.org/10.1001/jama.2009.1582.

23. Foulkes W, Rees J, Sewry C. Influenza a and rhabdomyolysis. J Inf Secur. 1990;21(3):303-4. https://doi.org/10.1016/0163-4453(90)94077-d.

24. Fadila MF, Wool KJ. Rhabdomyolysis secondary to influenza a infection: a case report and review of the literature. N Am J Med Sci. 2015;7(3):122-4. https://doi.org/10.4103/1947-2714.1539269.

25. Ordofiez JC, Sånchez G, Le6n R, Ramos JM. Rhabdomyolysis and acute renal failure associated with influenza virus type a infection. Rabdomi61isis y fracaso renal Agudo asociado a infecci6n por el virus de la gripe a. Rev Clin Esp. 2015;215(5):295-6. https://doi.org/10.1016/j. rce.2014.11.00930.9

26. Hamano T, Matsunaga A, Yamamura O, et al. Influenza A (H3N2)induced rhabdomyolysis 310 complicating anterior compartment syndrome: Serial changes in muscle MRI T2 fat suppression imaging. eNeurologica/Sci. 2017;7:15-7. Published 2017 Mar 27. https://doi.org/10. 1016/j.ensci.2017.03.006.

27. Geladari E, Papademetriou V, Moore H, Lu D. A case of influenza type a myocarditis that presents with ST elevation MI, cardiogenic shock, acute renal failure, and rhabdomyolysis and with rapid recovery after treatment with oseltamivir and intra-aortic balloon pump support. Cardiovasc Revasc Med. 2018;19(1 Pt A):37-42. https://doi.org/10.1016/j. carrev.2017.04.017.

28. Ibrahim AM, Manthri S, Soriano PK, Bhatti V, Mamillapalli CK. Rhabdomyolysis Associated with Influenza A Virus Infection. Cureus. 2018; 10(6):e2786. Published 2018 Jun 11. https://doi.org/10.7759/cureus.2786.

29. Runnstrom M, Ebied AM, Khoury AP, Reddy R. Influenza-induced rhabdomyolysis. BMJ Case Rep. 2018;11(1):e226610. Published 2018 Dec 4. https://doi.org/10.1136/bcr-2018-226610

30. Sagan J, Siråöek $P$, Folwarczny $P$, Sporkovå M, Hurnik P. Severe Course of Influenza B 323 Complicated by Rhabdomyolysis and Acute
Respiratory Failure Resulting in Death. Klin Mikrobiol 324 Infekc Lek. 2018;24(4):118-20.

31. Odio CD, Mandimika C, Jabuonski TA, Malinis M. Severe Influenza A (HINI) Virus Infection Complicated by Myositis, Refractory Rhabdomyolysis, and Compartment Syndrome. Case Rep Med. 2019:1540761. Published 2019 Jan 30. https://doi.org/10.1155/2019/1540761.

32. Tan L, Wang $Q$, Zhang $D$, et al. Lymphopenia predicts disease severity of COVID-19: a descriptive and predictive study. Signal Transduct Target Ther. 2020;5(1):33. Published 2020 Mar 27. https://doi.org/10.1038/ s41392-020-0148-4.

\section{Publisher's Note}

Springer Nature remains neutral with regard to jurisdictional claims in published maps and institutional affiliations.
Ready to submit your research? Choose BMC and benefit from:

- fast, convenient online submission

- thorough peer review by experienced researchers in your field

- rapid publication on acceptance

- support for research data, including large and complex data types

- gold Open Access which fosters wider collaboration and increased citations

- maximum visibility for your research: over $100 \mathrm{M}$ website views per year

At BMC, research is always in progress.

Learn more biomedcentral.com/submissions 